\title{
ATP-sensitive potassium channels gene polymorphism rs1799858 affects the risk of macro-/micro-vascular arteriosclerotic event in patients with increased low-density lipoprotein cholesterol levels
}

\author{
Cheng Liu ${ }^{1,2^{*}} \mathbb{D}$, Tianwang Guan ${ }^{2}$, Yanxian Lai ${ }^{1}$, Jieming Zhu ${ }^{3}$, Jian Kuang ${ }^{4}$ and Yan Shen ${ }^{2}$
}

\begin{abstract}
Background: Plasma concentration of low-density lipoprotein cholesterol (LDL-C) is causally related to the risk of arteriosclerotic events. Whether ATP-sensitive potassium channels (KATP) genetic variants predict increased LDL-C concentration ( $\geq 1.8 \mathrm{mmol} / \mathrm{L}$ ) and risk of macro-/micro-vascular arteriosclerotic event remain elusive.

Methods: A total of 320 subjects with increased LDL-C concentration ( $\geq 1.8 \mathrm{mmol} / \mathrm{L})$ and 320 counterpart subjects $(<1.8 \mathrm{mmol} / \mathrm{L})$ from the South China were enrolled in this study. Three KATP polymorphisms (rs 1799858, rs4148671 and rs78148713) were genotyped by the Sequenom MassARRAY system. Binary logistic regression analysis was used to evaluate the association of the 3 KATP variants with increased LDL-C concentration and carotid artery stenosis (CAS) $\geq 50 \%$. Two-way ANOVA was used to analyze the association of the 3 KATP variants with microalbumin in urine (MAU) and high-sensitivity C-reactive protein (HsCRP) levels. Cox proportional hazards regression analysis was used to retrospectively analyse the association of the optimal variant with the risk of new onset/recurrent acute myocardial infarction (AMI).
\end{abstract}

Results: Among the 3 studied KATP gene single nucleotide polymorphisms (SNPs), only rs1799858 (TT + CT genotype) was associated with elevated risk of $L D L-C \geq 1.8 \mathrm{mmol} / \mathrm{L}$ (adjusted $\mathrm{OR}=2.25,95 \% \mathrm{Cl}: 1.31-3.85, P=0.003$ ) and CAS $\geq 50 \%$ (adjusted $\mathrm{OR}=2.80,95 \% \mathrm{Cl}: 1.12-6.98, P=0.028$ ). KATP SNP rs 1799858 was also associated with increased MAU $(P=0.013)$ and HsCRP $(P=0.027)$ levels. The follow-up for an average of 51.1-months revealed that participants carrying the T-allele $(T+C T)$ of rs 1799858 was associated with high risk of new onset/recurrent AMl (adjusted HR=2.90, 95\% Cl: 1.06-7.94, $P=0.038$ ).

(Continued on next page)

\footnotetext{
* Correspondence: eyliucheng@scut.edu.cn

'Department of Cardiology, Guangzhou First People's Hospital, School of

Medicine, South China University of Technology, 1 Panfu road, Guangzhou 510180, China

2Department of Cardiology, Guangzhou First People's Hospital, Guangzhou Medical University, Guangzhou 510180, China

Full list of author information is available at the end of the article
}

(c) The Author(s). 2020 Open Access This article is licensed under a Creative Commons Attribution 4.0 International License, which permits use, sharing, adaptation, distribution and reproduction in any medium or format, as long as you give appropriate credit to the original author(s) and the source, provide a link to the Creative Commons licence, and indicate if changes were made. The images or other third party material in this article are included in the article's Creative Commons licence, unless indicated otherwise in a credit line to the material. If material is not included in the article's Creative Commons licence and your intended use is not permitted by statutory regulation or exceeds the permitted use, you will need to obtain permission directly from the copyright holder. To view a copy of this licence, visit http://creativecommons.org/licenses/by/4.0/ The Creative Commons Public Domain Dedication waiver (http://creativecommons.org/publicdomain/zero/1.0/) applies to the data made available in this article, unless otherwise stated in a credit line to the data. 


\begin{abstract}
(Continued from previous page)
Conclusion: The KATP SNP rs1799858 may be an optimal genetic predisposition marker for increased LDL-C concentration ( $\geq 1.8 \mathrm{mmol} / \mathrm{L})$ and its related macro-/micro-vascular arteriosclerotic event risk. The KATP variant rs1799858 was associated with higher risk of macro-/micro-vascular arteriosclerotic events in patients with elevated serum LDL-C levels.
\end{abstract}

Keywords: ATP-sensitive potassium channels, Polymorphism, Low-density lipoprotein cholesterol, Myocardial infarction, Microalbumin in urine

\section{Background}

The low-density lipoprotein cholesterol (LDL-C) is considered "bad" cholesterol because an increase in its plasma concentration is an independent risk factor for atherosclerotic cardiovascular events, which is still a major global health problem [1]. Decreased LDL-C level was significantly associated with decreased risk for macro-/microvascular arteriosclerotic events. A couple of the methods such as dietary control, bowel surgery and lipid-lowering drugs (especially statins) are currently used for reducing LDL-C level. However, despite achieving both a lower target of $<1.8 \mathrm{mmol} / \mathrm{L}$ and an LDL-C reduction of at least $50 \%$ from the currently recommended baseline (LDL-C is between 1.8 and $3.5 \mathrm{mmol} / \mathrm{L}$ ) [2], high residual risk remains in patients receiving intensive statin therapies [3]. The Mendelian randomization showed that moderate decrease in LDL-C levels $(1.0 \mathrm{mmol} / \mathrm{L})$ prevent the development of cardiovascular disease during up to 30 years of follow-up, but it is also affected by mutations in lipid metabolism-related genes [4]. These suggest that statin therapy decreases the incidence of cardiovascular events, but the benefits may be dampened or offset by high genetic risks [5]. Thus, early genetic risk identification of populations at higher risk of increased LDL-C levels will provide a possible measure for early prevention from arteriosclerotic events.

Many candidate genes have been implicated in predisposition to increased levels of LDL-C. In recent years genes of the ATP-sensitive potassium channels (KATP) have received lots of attention. KATP is a type of potassium channel, which are hetero-octameric protein complexes comprising 4 pore-forming subunits (inwardly-rectifying $\mathrm{K}^{+}$channel, Kir6.x) and 4 regulatory subunits (sulfonylurea receptor, SURx), and are widely present in the heart, skeletal muscles, vascular smooth muscles, brain and pancreatic $\beta$-cells. KATP are not only critical high-fidelity metabolic sensors but also key end effectors of ischemic protection (especially in cardiac and cerebral ischemia) [6]. Hence, KATP, as gated channels coupling metabolism with ischemic protection, have become a promising new prevention and treatment target for atherosclerotic cardiovascular disease (ASCVD). The obligate octameric arrangement result from coregulation of expression on inward-rectifier potassium channel (Kir6.x) subunits (Kir6.1 and Kir6.2, encoded respectively by KCNJ8 and KCNJ11) and sulfonylurea receptor (SURx) subunits (SUR1 and SUR2, encoded respectively by $\mathrm{ABCC} 8$ and $\mathrm{ABCC} 9$ ) [7]. KCNJ8 and ABCC9 are immediately adjacent to one another on human chromosome 12p12.1, whereas KCNJ11 and ABCC8 are directly adjacent to each other on human chromosome 11p15.1. The KATP subunit constitution may change with different physiological or pathological conditions, resulting from alternative splicing of the 4 coding genes, which produce different subunits that varies in function under different conditions. In rat model the increased plasma triglyceride (TRIG) levels were reduced by a KATP opener [8], and high-fat diet-feeding induced elevation in plasma TRIG and TRIG-rich verylow-density lipoproteins were restored by direct activation of KATP via the hepatic vagus [9]. ATP-binding cassette transporter $\mathrm{A} 1$ (ABCA1) is the key regulator of high-density lipoprotein cholesterol (HDL-C) [10] and apolipoprotein AI (Apo AI) [11] metabolism, while the SUR1 subunit is the same structure as ABCA1 and belongs to ATP-binding cassette superfamily, which has similar functions to ABCA1 in regulating HDL-C metabolism [10]. On the other hand, Ling et al. [12] found that the up-regulation of KATP in monocytes/macrophages correlated with increased inflammation in vulnerable plaques. Fan et al. [13] also found that smoking induced atherosclerosis was rescued by the inhibition of KATP. In rat model of myocardial infarction (MI) the cardiac protective effect of dodecafluoropentane emulsion was shown to be KATP-dependent [14], and the KATP activation by nicorandil significantly reduced the incidence of all cardiovascular events (including cardiovascular death, non-fatal MI, non-fatal stroke, or unplanned hospital admission for cardiac chest pain, etc) by $14 \%$ in patients with stable angina during 1.6-year follow up [15]. In a rat model of ischemic stroke there was larger infarct areas and more severe brain edema and neurological deficits due to astrocytic Kir6.1 knockout [16]. These suggest that KATP is an important link in the development from dyslipidemia to macro-/micro-vascular arteriosclerotic diseases. 
Importantly, the KATP gene exhibits characteristics with high level of genetic polymorphism. KATP polymorphisms not only associated with dyslipidemia (e.g., higher levels of triglyceride (TIRG), total cholesterol (TC) and LDL-C as well as lower HDL-C) [17-19], essential hypertension (EH) [20] and ASCVD (e.g., MI and stroke) [21, 22] but also exhibited geographical and ethnic diversity (e.g., Africans, Europeans, East Asians). However, the relationship of KATP single nucleotide polymorphisms (SNPs) with increased LDL-C levels and its related macro-/micro-vascular arteriosclerotic events in China is rarely reported. Theoretically, there is a common genetic basis for dyslipidemia, $\mathrm{EH}$ and its related atherosclerotic cardiovascular events $[23,24]$. The present study was undertaken to investigate the possible relationships of KATP gene SNPs with the risk of increased LDL-C levels ( $\geq 1.8 \mathrm{mmol} / \mathrm{L})$ and macro-/microvascular arteriosclerotic events in South China.

\section{Materials and methods Study participants}

This study was by the Ethics Committee of Guangzhou First People's Hospital, School of Medicine, South China University of Technology (K-2017-043-02). A total of 320 subjects with increased LDL-C level $(\geq 1.8 \mathrm{mmol} / \mathrm{L})$ and 320 counterpart subjects $(<1.8 \mathrm{mmol} / \mathrm{L})$ from the South China were enrolled in the study. All participants with different types of dyslipidemia were newly diagnosed according to guidelines [2], including high levels of LDL-C $(\geq 1.8 \mathrm{mmol} / \mathrm{L})$, TRIG $(\geq 1.7 \mathrm{mmol} / \mathrm{L}), \quad$ TC $(\geq 5.2 \mathrm{mmol} / \mathrm{L}$ ) or (and) apolipoprotein B (Apo B $\geq 80$ $\mathrm{mg} / \mathrm{dL}$ ), and (or) low levels of HDL-C $(<1.0 \mathrm{mmol} / \mathrm{L})$ and Apo AI $(<120 \mathrm{mg} / \mathrm{dL})$. All participants with the coexisting $\mathrm{EH}$, coronary atherosclerotic heart disease (CAD), type 2 diabetes mellitus (T2D) or (and) atrial fibrillation (AF) were also recently diagnosed according to relevant guidelines (details guidelines information was presented in methods section of Additional file 1). Clinical data were collected from patient interviews, review of medical records and contact with treating physicians. All blood biochemistry analysis was conducted on admission to the study by using standard analytical techniques. Cardiac and bilateral carotid ultrasonography were performed on admission to the study according to the recommendations from the American Society of Echocardiography [25] and the North American Symptomatic Carotid Endarterectomy Trial [26], respectively.

\section{Genotyping assay}

Three KATP SNPs (rs1799858, rs4148671 and rs78148713) were genotyped using the MassARRAY system (Sequenom) according to the manufacturer's instructions with minor modifications based on literatures and human genome sequence databases [27]. Primers for the 3 KATP SNPs were designed based upon sequence information from GenBank using Primer 5.0 (Whitehead Institute Cambridge, Massachusetts, USA) according to the KATP gene sequence in GenBank [NC_ 000011.10, NC_000012.12 and NC_000012.11 (Additional file 1: Table S1)]. The primers were synthesized by Invitrogen Life Science Technologies (Guangzhou, China). The accuracy of the genotypes determined was $100 \%$ for each KATP SNP as described above.

\section{Long-term follow-up endpoint}

Primary outcome was new onset/recurrent acute myocardial infarction (AMI) including ST segment elevation MI and non ST segment elevation MI [28], and was diagnosed according to the guidelines at the time. The following three types of information sources were used to identify the primary outcome: participants and their families, medical records and the Center for Disease Control and Prevention. Patients were enrolled in the study from the date of first diagnosis of dyslipidemia, EH, CAD, T2D or (and) AF. Moreover, patient's AMIfree event survival time was calculated from the date of entry to the date of first diagnosis AMI, recurrent AMI or last follow-up. The date of final follow-up was December 31, 2019.

\section{Statistical analysis}

All analysis was using SPSS version 24 (SPSS, Chicago, IL). The Hardy-Weinberg equilibrium was assessed with a Chi-square test for control subjects as shown in Additional file 1: Table S2. Categorical variables [gender, smoking, drinking, $\mathrm{EH}, \mathrm{CAD}, \mathrm{T} 2 \mathrm{D}, \mathrm{AF}$, high LDL-C $(\geq 1.8 \mathrm{mmol} / \mathrm{L})$, high TRIG $(\geq 1.7 \mathrm{mmol} / \mathrm{L})$, high TC $(\geq 5.2 \mathrm{mmol} / \mathrm{L})$, low HDL-C $(<1.0 \mathrm{mmol} / \mathrm{L})$, high Apo B $(\geq 80 \mathrm{mg} / \mathrm{dL})$, low Apo AI $(<120 \mathrm{mg} / \mathrm{dL})$, carotid artery stenosis (CAS) $\geq 50 \%$ and new-onset/recurrent AMI] were presented as frequencies. The associations between each KATP SNP and these categorical variables were analyzed using the Chi square test. Binary logistic regression analysis was used to evaluate the Odds ratio (OR) of these types of dyslipidemia and CAS $\geq 50 \%$. Given that false positive might exist in the results, Bonferroni adjustment was used to adjust the significance thresholds for multinomial logistic regression. The Cox proportional hazards regression analysis for event free analysis of new onset/recurrent AMI was used to estimate the crude and adjusted hazard ratios (HRs) as well as the 95\% confidence intervals (CIs) with adjustments for potential covariates. Continuous variables were presented as mean $\pm \mathrm{SD}$. The differences between continuous variables between the two groups were evaluated by twoway ANOVA or independent-sample t-test. $P$ values of less than 0.05 were considered as statistically significant. All probabilities are two-tailed estimated. 


\section{Result}

\section{Characteristics of the study participants}

As shown in Table 1, participants with or without increased LDL-C level $(\geq 1.8 \mathrm{mmol} / \mathrm{L})$ showed significant differences in the levels of TRIG $(P=0.003)$, TC $(P<0.001)$, Apo B $(P<0.001)$, microalbumin in urine (MAU, $P<0.001$ ) and high-sensitivity $C$-reactive protein (HsCRP, $P=0.009$ ).

\section{Association between KATP SNPs and elevated LDL-C $(\geq 1.8$ $\mathrm{mmol} / \mathrm{L}$ )}

As shown in Table 2, KATP SNP rs1799858 (TT + CT genotype) was associated with elevated risk of high LDLC $(\geq 1.8 \mathrm{mmol} / \mathrm{L})$ levels (adjusted $\mathrm{OR}=2.25,95 \% \mathrm{CI}$ : $1.31-3.85, P=0.003)$.

\section{Association between KATP SNPs and CAS $\geq \mathbf{5 0} \%$}

As shown in Table 3, KATP SNP rs1799858 (TT + CT genotype) was associated with increased risk of CAS $\geq 50 \%$ (adjusted $\mathrm{OR}=2.80,95 \% \mathrm{CI}: 1.12-6.98, P=0.028$ ).

\section{Association between KATP SNPs and MAU level}

As shown in Table 4, participants with the increased LDL-C risk genotype of rs1799858 (TT + CT) was associated with elevated MAU level $(P=0.001$ and $<0.001)$ whereas rs4148671 (both $P>0.05$ ) and rs78148713 (both $P>0.05)$ were not significantly associated.

\section{Association between KATP SNPs and HsCRP level}

As shown in Table 5, participants with the increased LDL-C risk genotype of rs1799858 (TT $+\mathrm{CT}$ ) was associated with elevated HsCRP level $(P=0.018$ and 0.008$)$ whereas rs4148671 (both $P>0.05$ ) and rs78148713 (both $P>0.05)$ were not significantly associated.

\section{Association between KATP SNP rs1799858 and new- onset/recurrent AMI}

As shown in Fig. 1, participants carrying T-allele (TT + CT) of rs1799858 was associated with higher risk of new-onset/recurrent AMI (adjusted $\mathrm{HR}=2.90$, 95\% CI: 1.06-7.94, $P=0.038$ ) during an average follow-up of 51.1-months.

\section{Discussion}

This study is the first to address the possible associations of KATP gene SNPs with different types of dyslipidemia in south China. The data reported in this study indicate that none of the 3 KATP SNPs is associated with increased levels of TRIG $(\geq 1.7 \mathrm{mmol} / \mathrm{L}$, Additional file 1: Table S3), TC ( $\geq 5.2 \mathrm{mmol} / \mathrm{L}$, Additional file 1: Table S4) and Apo B ( $\geq 80 \mathrm{mg} / \mathrm{dL}$, Additional file 1: Table S6) as well as decreased levels of HDL-C $(<1.0 \mathrm{mmol} / \mathrm{L}$, Additional file 1: Table S5) and Apo AI $(<120 \mathrm{mg} / \mathrm{dL}$, Additional file 1: Table S7). Importantly, the data indicate
Table 1 Baseline characteristics of study participants

\begin{tabular}{|c|c|c|c|}
\hline & $\mathrm{LDL}-\mathrm{C}<1.8 \mathrm{mmol} / \mathrm{L}$ & $\mathrm{LDL}-\mathrm{C} \geq 1.8 \mathrm{mmol} / \mathrm{L}$ & $\boldsymbol{P}$ value \\
\hline N & 320 & 320 & - \\
\hline Male: Female & $232: 88$ & 217:103 & 0.195 \\
\hline Age $(Y)$ & $65.2 \pm 11.3$ & $65.5 \pm 11.1$ & 0.748 \\
\hline Smoking (\%) & $143(44.7)$ & $150(46.9)$ & 0.579 \\
\hline Drinking (\%) & $40(12.5)$ & $44(13.8)$ & 0.640 \\
\hline SBP $(m m H g)$ & $139.4 \pm 21.2$ & $142.4 \pm 23.8$ & 0.098 \\
\hline $\mathrm{DBP}(\mathrm{mmHg})$ & $77.4 \pm 13.1$ & $78.5 \pm 13.0$ & 0.278 \\
\hline BMI $\left(\mathrm{kg} / \mathrm{m}^{2}\right)$ & $24.5 \pm 4.2$ & $24.8 \pm 4.3$ & 0.394 \\
\hline \multicolumn{4}{|l|}{ Medical condition } \\
\hline $\mathrm{EH}(\%)$ & $214(66.9)$ & $236(73.8)$ & 0.057 \\
\hline CAD (\%) & $266(83.1)$ & $255(79.7)$ & 0.264 \\
\hline T2D (\%) & $174(54.4)$ & $174(54.4)$ & 1.000 \\
\hline AF $(\%)$ & $10(3.1)$ & $17(5.3)$ & 0.169 \\
\hline \multicolumn{4}{|c|}{ Blood biochemical index } \\
\hline TRIG (mmol/L) & $1.46 \pm 1.01$ & $1.70 \pm 1.00$ & 0.003 \\
\hline $\mathrm{TC}(\mathrm{mmol} / \mathrm{L})$ & $3.27 \pm 0.70$ & $4.70 \pm 1.12$ & $<0.001$ \\
\hline $\mathrm{HDL}-\mathrm{C}(\mathrm{mmol} / \mathrm{L})$ & $1.07 \pm 0.29$ & $1.08 \pm 0.23$ & 0.507 \\
\hline Apo B (mg/dL) & $64.9 \pm 21.4$ & $100.4 \pm 33.0$ & $<0.001$ \\
\hline Apo A1 (mg/dL) & $102.4 \pm 23.7$ & $103.4 \pm 23.3$ & 0.560 \\
\hline WBC $\left(\times 10^{9} / \mathrm{L}\right)$ & $8.31 \pm 2.90$ & $8.32 \pm 2.61$ & 0.962 \\
\hline $\mathrm{HGB}(\mathrm{g} / \mathrm{L})$ & $132.3 \pm 18.8$ & $129.8 \pm 17.2$ & 0.076 \\
\hline $\operatorname{PLT}\left(\times 10^{9} / \mathrm{L}\right)$ & $228.6 \pm 64.0$ & $237.4 \pm 66.3$ & 0.088 \\
\hline $\mathrm{FBG}(\mathrm{mmol} / \mathrm{L})$ & $5.48 \pm 1.20$ & $5.62 \pm 1.48$ & 0.173 \\
\hline P2hBS (mmol/L) & $9.01 \pm 2.71$ & $8.96 \pm 2.66$ & 0.825 \\
\hline $\mathrm{HbA1C}(\%)$ & $6.0 \pm 1.1$ & $6.0 \pm 1.3$ & 0.926 \\
\hline $\operatorname{Scr}(\mu \mathrm{mol} / \mathrm{L})$ & $92.0 \pm 46.9$ & $89.7 \pm 34.0$ & 0.468 \\
\hline BUN (mmol/L) & $5.72 \pm 2.09$ & $5.81 \pm 1.97$ & 0.569 \\
\hline UA $(\mu \mathrm{mol} / \mathrm{L})$ & $402.1 \pm 107.8$ & $397.4 \pm 104.6$ & 0.573 \\
\hline $\operatorname{ALT}(U / L)$ & $25.7 \pm 24.3$ & $27.3 \pm 34.4$ & 0.483 \\
\hline AST (U/L) & $47.9 \pm 112.8$ & $52.3 \pm 105.4$ & 0.612 \\
\hline Alb (g/L) & $37.2 \pm 3.5$ & $36.7 \pm 4.9$ & 0.104 \\
\hline $\mathrm{Na}^{+}(\mathrm{mmol} / \mathrm{L})$ & $140.3 \pm 3.4$ & $140.2 \pm 3.2$ & 0.613 \\
\hline $\mathrm{K}^{+}(\mathrm{mmol} / \mathrm{L})$ & $3.76 \pm 0.38$ & $3.74 \pm 0.43$ & 0.416 \\
\hline $\mathrm{HsCRP}(\mathrm{mg} / \mathrm{L})$ & $10.9 \pm 11.1$ & $14.2 \pm 19.1$ & 0.009 \\
\hline MAU $(A C R, m g / g)$ & $229.0 \pm 392.2$ & $355.1 \pm 480.2$ & $<0.001$ \\
\hline $\mathrm{HCY}(\mu \mathrm{mol} / \mathrm{L})$ & $14.7 \pm 5.7$ & $14.2 \pm 5.9$ & 0.342 \\
\hline ACE (U/L) & $35.1 \pm 23.2$ & $33.6 \pm 20.1$ & 0.380 \\
\hline Renin (pg/mL) & $27.1 \pm 28.5$ & $25.5 \pm 27.2$ & 0.479 \\
\hline Ang I (ng/L) & $2.40 \pm 1.79$ & $2.51 \pm 1.38$ & 0.427 \\
\hline Ang $\|(n g / L)$ & $64.4 \pm 85.0$ & $58.0 \pm 78.9$ & 0.325 \\
\hline ALD (ng/L) & $171.0 \pm 120.1$ & $170.2 \pm 88.3$ & 0.928 \\
\hline \multicolumn{4}{|l|}{ Echocardiography } \\
\hline RVD (cm) & $1.73 \pm 0.19$ & $1.75 \pm 0.17$ & 0.296 \\
\hline $\operatorname{RAD}(\mathrm{cm})$ & $3.36 \pm 0.30$ & $3.31 \pm 0.30$ & 0.064 \\
\hline
\end{tabular}


Table 1 Baseline characteristics of study participants (Continued)

\begin{tabular}{llll}
\hline & LDL-C $<1.8 \mathrm{mmol} / \mathrm{L}$ & LDL-C $\geq 1.8 \mathrm{mmol} / \mathrm{L}$ & $\boldsymbol{P}$ value \\
\hline LVD (cm) & $4.83 \pm 0.58$ & $4.76 \pm 0.54$ & 0.095 \\
LAD (cm) & $3.11 \pm 0.56$ & $3.07 \pm 0.57$ & 0.336 \\
LVEF (\%) & $55.9 \pm 10.8$ & $56.7 \pm 8.5$ & 0.276 \\
\hline
\end{tabular}

that the risk of increase in LDL-C levels $(\geq 1.8 \mathrm{mmol} / \mathrm{L})$ in participants with $\mathrm{T}$-allele $(\mathrm{TT}+\mathrm{CT})$ increases by 1.25-fold compared with those with $\mathrm{CC}$ genotype except for rs4148671 and rs78148713 variants. Dyslipidemia is a heterogeneous disease. The findings in this study are partially consistent with the study by Engwa et al. [17] reporting that the TT genotype of rs1799854 is related to high levels of HDL and low levels of TC, TG and LDL in non-diabetic patients among Nigerians, and with the study by Nikolac et al. [18] reporting that rs1799859 and rs1799854 were related to higher TRIG level in Croatia T2D patients with sulfonylurea therapy, and with the study by $\mathrm{Xu}$ et al. [19] reporting that the $\mathrm{K}$ allele $(\mathrm{KK}+\mathrm{EK})$ of rs5219 is associated with a higher ratio of TC vs. HDL-C in prediabetic youth Han Chinese.

Atherogenic dyslipidemia-characterized by preponderance of small, dense, LDL-C is the major cause of macrovascular arteriosclerotic disease. CAS $\geq 50 \%$ is now recognized as a new subtype of macrovascular arteriosclerotic disease besides CHD and stroke [29]. This is based on findings that the 10-year risk of ASCVD in patients with CAS $\geq 50 \%$ is concordant with those in patients suffering from cardiovascular disease. This study further elucidate that participants with high LDL-C risk genotype of rs11046182 (TT + CT) also associated with high risk of CAS $\geq 50 \%$ (increased approximately by 1.8 fold). In addition to macrovascular arteriosclerotic disease, recent studies show an association between increased LDL-C level and microvascular arteriosclerotic disease (e.g., coronary [30] and renal [31]). The MAU is a key biomarker of microvascular injury in chronic kidney disease and is an independent risk factor of cardiovascular events [32]. This study indicates an association between high LDL-C risk genotype $(\mathrm{TT}+\mathrm{CT})$ of rs1799858 and the increase in MAU levels.

Whether it is macrovascular arteriosclerotic diseases or microvascular diseases, inflammation pathways play an important role in the pathogenesis of atherosclerosis caused by abnormal LDL-C level. Recently, the Canakinumab Anti-inflammatory Thrombosis Outcome Study (CANTOS) [33] indicated that decreasing inflammation with canakinumab, an interleukin- $1 \beta$ neutralizing monoclonal antibody, reduced cardiovascular events independent of cholesterol level [34]. On the other hand, methotrexate (MTX) exerts anti-inflammatory effects through its intracellular metabolite (polyglutamate methotrexate) and may help in preventing atherosclerotic events. However, low-doses of MTX do not reduce inflammatory factor levels (e.g., interleukin-1 $\beta$, interleukin-6, or C-reactive protein) and the risk of ASCVD among patients with stable atherosclerosis [35]. Low-doses of colchicine decrease ischemic cardiovascular events by $23 \%$ among patients with recent myocardial infarction [36]. These results suggest that it is necessary to screen appropriate populations (high inflammation risk) for receiving anti-inflammatory treatment besides the differences in anti-inflammatory drugs used. This study indicates that the high LDL-C risk genotype of rs1799858 (TT + CT) associates with increased levels of the anti-inflammation marker HsCRP. Previous studies have indicated that the HsCRP levels are not only related to cardiovascular disease independent of traditional risk factors, but also can independently predict the occurrence and recurrence of adverse cardiovascular events $[37,38]$. This study is the first to report that the high risk of increased LDL-C and HsCRP related $\mathrm{T}$ allele $(\mathrm{TT}+\mathrm{CT})$ of rs1799858 associate with higher risk of new-onset/recurrent AMI (increased approximately by 1.9-fold) after an average follow-up of 51.1-months. These observations suggest that rs1799858 may be genetic factor that predispose patients to atherogenic dyslipidemia (increased LDL-C level) related macro-/micro-vascular arteriosclerotic event risk.

Table 2 Association between KATP SNPs and elevated LDL-C ( $\geq 1.8 \mathrm{mmol} / \mathrm{L})$ in study participants

\begin{tabular}{|c|c|c|c|c|c|c|c|c|c|}
\hline \multirow[t]{2}{*}{ KATP SNPS } & & \multicolumn{2}{|c|}{$\mathrm{LDL}-\mathrm{C} \geq 1.8 \mathrm{mmol} / \mathrm{L}(\mathrm{N} / \%)$} & \multirow{2}{*}{$\begin{array}{l}\text { Crude } \\
\text { OR }(95 \% \mathrm{Cl})\end{array}$} & \multirow{2}{*}{$\begin{array}{l}\text { Crude } \\
\boldsymbol{P} \\
\text { value }\end{array}$} & \multirow{2}{*}{$\begin{array}{l}\text { Adjusted } \\
\text { OR }(95 \% \mathrm{Cl})^{\mathrm{a}}\end{array}$} & \multirow{2}{*}{$\begin{array}{l}\text { Adjusted } \\
\boldsymbol{P} \text { value }^{\mathrm{a}}\end{array}$} & \multirow{2}{*}{$\begin{array}{l}\text { Adjusted } \\
\text { OR }(95 \% \text { Cl) }\end{array}$} & \multirow{2}{*}{$\begin{array}{l}\text { Adjusted } \\
\boldsymbol{P} \text { value }^{\mathbf{b}}\end{array}$} \\
\hline & & NO & YES & & & & & & \\
\hline \multirow[t]{2}{*}{ rs1799858 } & $C C$ & $218(68.1)$ & $202(63.1)$ & 1.00 & & 1.00 & & 1.00 & \\
\hline & $\pi+C T$ & $102(31.9)$ & $118(36.9)$ & $1.25(0.90-1.73)$ & 0.183 & $1.50(1.04-2.16)$ & 0.032 & $2.25(1.31-3.85)$ & 0.003 \\
\hline \multirow[t]{2}{*}{ rs4148671 } & CC & $276(86.3)$ & $288(90.0)$ & 1.00 & & 1.00 & & 1.00 & \\
\hline & $\pi+C T$ & $44(13.8)$ & $32(10.0)$ & $0.70(0.43-1.13)$ & 0.144 & $0.72(0.42-1.23)$ & 0.224 & $0.61(0.35-1.06)$ & 0.078 \\
\hline \multirow[t]{2}{*}{ rs78148713 } & $C C+C T$ & $20(6.3)$ & $12(3.8)$ & $0.58(0.28-1.22)$ & 0.151 & $0.51(0.24-1.11)$ & 0.091 & $0.96(0.34-2.72)$ & 0.935 \\
\hline & $\pi$ & 300 (93.7) & 308 (96.2) & 1.00 & & 1.00 & & 1.00 & \\
\hline
\end{tabular}

a Model 1: After adjustment for gender, age, smoking, drinking, WBC, BMI, EH, T2D, liver function (ALT, AST and Alb), renal function (Scr, BUN and UA), HsCRP, $\mathrm{HbA} 1 \mathrm{C}, \mathrm{HCY}$, and RAAS activity (ACE, renin, Ang I, Ang II and ALD)

${ }^{\mathrm{b}}$ Model 2: It is the same as Model 1, and also including dyslipidemia (TRIG, TC, Apo B, HDL-C and Apo Al) 
Table 3 Association between KATP SNPs and CAS $\geq 50 \%$ in study participants

\begin{tabular}{|c|c|c|c|c|c|c|c|c|c|}
\hline \multirow[t]{2}{*}{ KATP SNPS } & & \multicolumn{2}{|c|}{ CAS $\geq 50 \%(N / \%)$} & \multirow{2}{*}{$\begin{array}{l}\text { Crude } \\
\text { OR }(95 \% \mathrm{Cl})\end{array}$} & \multirow{2}{*}{$\begin{array}{l}\text { Crude } \\
\boldsymbol{P} \\
\text { value }\end{array}$} & \multirow{2}{*}{$\begin{array}{l}\text { Adjusted } \\
\text { OR }(95 \% \mathrm{Cl})^{\mathrm{a}}\end{array}$} & \multirow{2}{*}{$\begin{array}{l}\text { Adjusted } \\
\boldsymbol{P} \text { value }^{\mathrm{a}}\end{array}$} & \multirow{2}{*}{$\begin{array}{l}\text { Adjusted } \\
\text { OR }(95 \% \text { Cl) }\end{array}$} & \multirow{2}{*}{$\begin{array}{l}\text { Adjustec } \\
\boldsymbol{P} \text { value }\end{array}$} \\
\hline & & NO & YES & & & & & & \\
\hline \multirow[t]{2}{*}{ rs1799858 } & $C C$ & 408 (66.6) & $12(44.4)$ & 1.00 & & 1.00 & & 1.00 & \\
\hline & $\pi+C T$ & 205 (33.4) & 15 (55.6) & $2.49(1.14-5.41)$ & 0.022 & $2.74(1.09-6.88)$ & 0.032 & $2.80(1.12-6.98)$ & 0.028 \\
\hline \multirow[t]{2}{*}{ rs4148671 } & $C C$ & $542(88.4)$ & $22(81.5)$ & 1.00 & & 1.00 & & 1.00 & \\
\hline & $\pi+C T$ & 71 (11.6) & $5(18.5)$ & $1.74(0.64-4.73)$ & 0.281 & $2.35(0.69-8.15)$ & 0.178 & $2.60(0.74-9.12)$ & 0.136 \\
\hline \multirow[t]{2}{*}{ rs78148713 } & $C C+C T$ & $30(4.9)$ & $2(7.4)$ & $1.56(0.35-6.87)$ & 0.561 & $1.26(0.24-6.59)$ & 0.782 & $1.34(0.25-7.04)$ & 0.734 \\
\hline & $\pi$ & $583(95.1)$ & 25 (92.6) & 1.00 & & 1.00 & & 1.00 & \\
\hline
\end{tabular}

${ }^{a}$ Model 1: After adjustment for gender, age, smoking, drinking, WBC, BMI, EH, T2D, liver function (ALT, AST and Alb), renal function (Scr, BUN and UA), HsCRP, $\mathrm{HbA1C}, \mathrm{HCY}$, and RAAS activity (ACE, renin, Ang I, Ang II and ALD)

${ }^{\mathrm{b}}$ Model 3: It is the same as Model 1, and also including dyslipidemia (TRIG, TC, LDL-C, Apo B, HDL-C and Apo Al)

Currently, the mechanism by which KATP variant increases LDL-C levels and its related macro-/micro-vascular arteriosclerotic event risk remains unclear. This study reports no significant difference on SBP, BMI and postprandial two hours blood glucose (P2hBS) was observed between the two groups (Table 1), but the average levels of SBP $(>130 \mathrm{mmHg})$, BMI $\left(>24.0 \mathrm{~kg} / \mathrm{m}^{2}\right)$ and P2hBS ( $>7.8 \mathrm{mmol} / \mathrm{L})$ were higher than normal especially in high LDL-C ( $\geq 1.8 \mathrm{mmol} / \mathrm{L})$ group, which was also accompanied with high TRIG, TC and Apo B levels. This suggests that participants in the high LDL-C group suffer a state of metabolic syndrome (MeS). Insulin resistance (IR) plays a primary role in the pathogenesis of $\mathrm{MeS}$, leading to dyslipidemia and its related ASCVD [39]. Indeed, Wan et al. [40] reported that rs5219 is associated with IR in vitro model (L6 rat skeletal muscle cell line), and Gonen et al. [41] further reported that KATP SNP rs1799854, rs1799859 and rs5219 play a key role in glucose-induced insulin secretion in Turkey while such association was not seen in participants from the Caribbean harboring the rs5219 variant [42] as well as participants from Polands harboring the rs1799854

Table 4 Association between KATP SNPs and MAU level in participants

\begin{tabular}{lllll}
\hline KATP SNPS & & $\mathrm{MAU}(\mathrm{ACR}, \mathrm{mg} / \mathrm{g})$ & \\
\cline { 3 - 5 } & & $\mathrm{LDL}-\mathrm{C}<1.8 \mathrm{mmol} / \mathrm{L}$ & $\mathrm{LDL}-\mathrm{C} \geq 1.8 \mathrm{mmol} / \mathrm{L}$ & $\boldsymbol{P}$ value \\
\hline rs1799858 & $C C$ & $231.2 \pm 440.2$ & $286.2 \pm 519.5$ & 0.241 \\
& $\pi+C T$ & $224.3 \pm 263.8$ & $473.2 \pm 377.7$ & $<0.001$ \\
& $P$ value & 0.885 & 0.001 & \\
rs4148671 & $C C$ & $211.1 \pm 382.6$ & $351.5 \pm 476.5$ & $<0.001$ \\
& $\pi+C T$ & $341.2 \pm 435.9$ & $388.0 \pm 518.7$ & 0.671 \\
& $P$ value & 0.067 & 0.684 & \\
rs78148713 & $C C+C T$ & $203.4 \pm 204.9$ & $463.5 \pm 552.0$ & 0.141 \\
& $\pi$ & $230.7 \pm 410.8$ & $350.9 \pm 477.7$ & 0.001 \\
& $P$ value & 0.764 & 0.426 & \\
\hline
\end{tabular}

${ }^{a} A C R$ urinary albumin-to-creatinine ratio variant [22]. The effects of KATP gene polymorphisms (mutations or variants) on IR are not fully understood, but it is tempting to speculate that the elevated activity of KATP as well as in the presence of the KATP rs1799858 variant, which directly impact the cardiovascular system, and influences the susceptibility to dyslipidemia and its related macro-/micro-vascular arteriosclerotic damages. Such influence can be tissue specific and attributes to tissue/cell-specific KATP variants expressed in the heart, skeletal/smooth muscles, pancreatic $\beta$-cells and the brain. AMI is an important cardiac subtype of ASCVD. The pathophysiological essence of AMI is myocardial ischemia that is the result of coronary artery ("macrovascular") obstruction (e.g., $\mathrm{CAD}$ ) and coronary microvascular obstruction (e.g., coronary microvascular dysfunction (CMD)). CMD, as a new microvascular paradigm, has been widespread before obstructive CAD is present in the epicardial coronary arteries, and plays the leading role in the pathophysiology of AMI. Imbalance in lipid metabolism is one of the initiating factors of CMD. Although the mechanism underlying CMD caused by dyslipidemia (e.g., LDL-C [43]) is not fully understood, existing

Table 5 Association between KATP SNPs and HsCRP level in participants

\begin{tabular}{|c|c|c|c|c|}
\hline \multirow[t]{2}{*}{ KATP SNPS } & & \multicolumn{3}{|l|}{ HsCRP (mg/L) } \\
\hline & & $\mathrm{LDL}-\mathrm{C}<1.8 \mathrm{mmol} / \mathrm{L}$ & $\mathrm{LDL}-\mathrm{C} \geq 1.8 \mathrm{mmol} / \mathrm{L}$ & $P$ value \\
\hline \multirow[t]{3}{*}{ rs1799858 } & CC & $10.7 \pm 10.7$ & $12.2 \pm 17.1$ & 0.295 \\
\hline & $\pi+C T$ & $11.2 \pm 11.8$ & $17.5 \pm 21.8$ & 0.008 \\
\hline & $P$ value & 0.712 & 0.018 & \\
\hline \multirow[t]{3}{*}{ rs4148671 } & CC & $10.8 \pm 11.3$ & $14.0 \pm 19.5$ & 0.016 \\
\hline & $\pi+C T$ & $11.5 \pm 9.8$ & $15.4 \pm 15.3$ & 0.211 \\
\hline & $P$ value & 0.677 & 0.688 & \\
\hline \multirow[t]{3}{*}{ rs78148713 } & $C C+C T$ & $13.6 \pm 6.7$ & $15.5 \pm 17.0$ & 0.719 \\
\hline & $\pi$ & $10.7 \pm 11.3$ & $14.1 \pm 19.2$ & 0.008 \\
\hline & $P$ value & 0.083 & 0.799 & \\
\hline
\end{tabular}




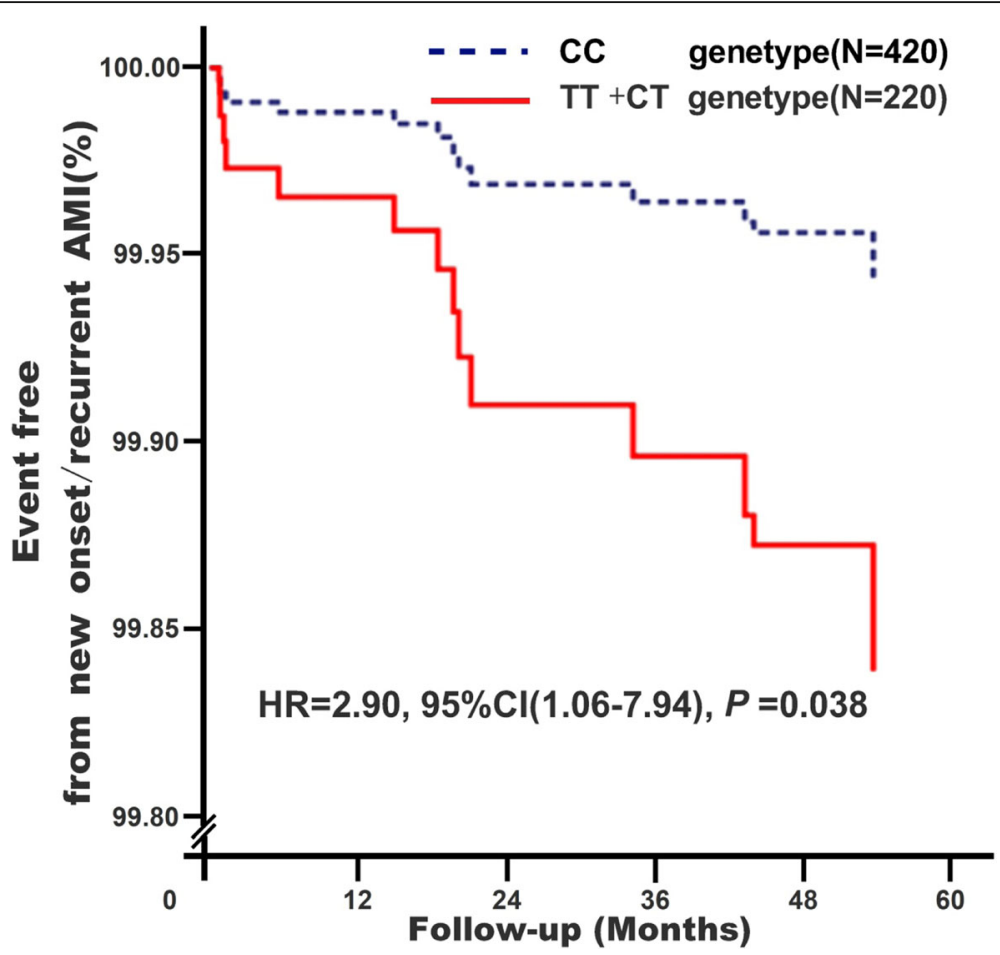

Fig. 1 Association between KATP rs1799858 and new-onset/recurrent AMI in participants*. *Model 4: After adjustment for gender, age, smoking, drinking, WBC, BMl, liver function (ALT, AST and Alb), renal function (Scr, BUN and UA), HsCRP, HbA1C, HCY, and RAAS activity (ACE, renin, Ang I, Ang II and ALD), dyslipidemia (TRIG, TC, LDL-C, Apo B, HDL-C and Apo Al), medical condition (EH, CAD, T2D and AF), NYHA functional classification, combined medication (antiplatelet drugs, warfarin, statins, RSIs, BBs, MRA, CCBs, diuretics, digoxin, nitrates, and hypoglycemic agents) and echocardiography index (RVD, RAD, LVD, LAD, and LVEF)

evidence suggests that it is associated with increased oxidative stress [44]. KATP is not only involved in the metabolic regulation of coronary vascular tone (e.g., coronary $K A T P$ ) but also in mediating oxidative stress (e.g., mitochondrial $K A T P)[45,46]$.

ASCVD (e.g., CAD) results from a cross-talk between environmental and genetic factors [47]. Although environmental factors (e.g., high-cholesterol diet) play a role in ASCVD, genetic factors are a major determinant of ASCVD. The genetic risk of ASCVD is conferred in part through known metabolic risk factors (e.g., dyslipidemia) [48]. ASCVD results in complex pathologies that develop over time due to genetic and environmental factors. To adapt to ever-changing gene-environment interactions, posttranslational regulations (e.g., microRNA [49]) have recently been valued as core contributors to ASCVD pathogenesis. SNPs have a huge impact on transcription, maturation and target specificity of miRNA. Hence, the mutation of the microRNA binding site in the target gene will affect the splicing efficiency and stability of mRNA (e.g., intron splicing enhancer, silencer element or conformation), regulates RAAS activity [50] and mediates cardiovascular injury, attributed to KATP SNPs (e.g., rs1799858). Based on the aforementioned, elucidating the specific regulatory mechanism has proven to be indispensable.

\section{Study strengths and limitations}

The strengths of the study were that this is the first time a direct association of KATP SNPs with the risk of increased LDL-C levels and macro-/micro-vascular arteriosclerotic events, and with the inter-individual variability of inflammatory state in arteriosclerotic related diseases. Another strength of this study was that it had a follow-up time of over 51 months, and evaluated risks associated with new-onset/recurrent acute coronary syndrome. This study was also hurdled by some limitations. Firstly, since the sample size of this study is not big enough $(N=640)$, large-scale prospective studies will help to further verify those findings. Secondly, Bonferroni adjustment was used to adjust the significance thresholds, but there was still the possibility of potential false-positive results especially for future research building on this study. Therefore, results must be interpreted carefully. 


\section{Conclusion}

KATP SNP rs1799858 may be a potential genetic susceptibility marker for increased LCL-C level and its related macro-/micro-vascular arteriosclerotic event risk. Therefore, genetic screening at the KATP SNP loci could potentially improve patient outcomes through early prevention or treatment for macro-/micro-vascular arteriosclerotic diseases with a much needed large-scale prospective study.

\section{Supplementary information}

Supplementary information accompanies this paper at https://doi.org/10. 1186/s12944-020-01315-6.

\section{Additional file 1: Additional Method and Results. Table S1. The} primers of KATP SNPs in the Sequenom MassARRAY system. Table S2. KATP SNPS in study participants. Table S3. Association of KATP SNPS with increased TRIG ( $\geq 1.7 \mathrm{mmol} / \mathrm{L}$ ) levels in study subjects. Table S4.

Association of KATP SNPS with increased TC ( $\geq 5.2 \mathrm{mmol} / \mathrm{L})$ levels in study participants. Table S5. Association of KATP SNPs with decreased HDL-C $(<1.0 \mathrm{mmol} / \mathrm{L})$ levels in study participants. Table S6. Association of KATP SNPs with increased Apo B ( $\geq 80 \mathrm{mg} / \mathrm{dL}$ ) levels in study subjects. Table S7. Association of KATP SNPS with decreased Apo Al (<120 mg/ $\mathrm{dL}$ ) levels in study participants. Table S8. Baseline characteristics of study participants at the end of the follow-up.

\section{Abbreviations}

ACE: Angiotensin converting enzyme; ACR: Urinary albumin-to-creatinine ratio; AF: Atrial fibrillation; Alb: Albumin; ALD: Aldosterone; ALT: Alanine aminotransferase; AMI: Acute myocardial infarction; Ang I/ II: Angiotensin I/II; Apo Al: Apolipoprotein Al; Apo B: Apolipoprotein B; ASCVD: Arteriosclerosis cardiovascular disease; AST: Aspartate aminotransferase; BMI: Body mass index; BUN: Blood urea nitrogen; CAS: Carotid artery stenosis; CAD: Coronary atherosclerotic heart disease; Cl: Confidence interval; CMD: Coronary microvascular dysfunction; DBP: Diastolic blood pressure; EH: Essential hypertension; FBG: Fasting blood glucose; HbA1C: Glycosylated hemoglobin; HDL-C: High-density lipoprotein cholesterol; HGB: Hemoglobin concentration; HR: Hazard ratio; HsCRP: High-sensitivity C-reactive protein; $\mathrm{K}^{+}$: Serum potassium; KATP : ATP-sensitive potassium channels; Kir6.x: Inwardrectifier potassium channel; LDL-C: Low-density lipoprotein cholesterol; MAF: Minor allele frequency; MAU: Microalbumin in urine; MeS: Metabolic syndrome; MI: Myocardial infarction; MTX: Methotrexate; $\mathrm{Na}^{+}$: Serum sodium; OR: Odds ratio; P2hBS: Postprandial blood glucose two hours; PLT: Platelet count; RAAS: Renin-angiotensin-aldosterone system; SBP: Systolic blood pressure; Scr: Serum creatinine; SNP: Single nucleotide polymorphism; SUR: Sulfonylurea receptor; TC: Total cholesterol; T2D: Type 2 diabetes mellitus; TRIG: Triglyceride; UA: Serum uric acid; WBC: White blood cell count

\section{Acknowledgements}

The authors wish to thank all the study participants from the South China Cardiovascular Related Disease Cohort (SCCDC, since July 2010), research staff and students who participated in this work.

\section{Authors' contributions}

$\mathrm{CL}$, literature search, study format, protocol writing, data collection, data processing, data interpretation, data analysis, manuscript writing; TWG, JMZ and $\mathrm{JK}$, literature search, patients recruitment, data interpretation and manuscript writing; YXL and JMZ, carrying out the molecular genetics; TWG and YS, patients recruitment, data collection; patients follow-up. The manuscript has been read and approved by all authors.

\section{Funding}

This study was funded by the National Natural Science Foundation of China (81100235), the Guangdong Natural Science Foundation of China (S201 1040004458), the Guangdong Science and Technology Planning Project of China (2014A020212372), the Guangzhou Science and Technology Project of China (2012 J4100035 and 201804010214) and xinxin-Merck Cardiovascular Scientific Research Fund (2017-CCA-xinxin merck fund-012).

\section{Availability of data and materials}

The datasets used and/or analyzed in this study are available from the corresponding author on reasonable request.

Ethics approval and consent to participate

The study received ethics approval from the Institutional Review Board of Guangzhou First People's Hospital.

\section{Consent for publication}

Not applicable.

\section{Competing interests}

The authors declare that they have no competing interests.

\section{Author details}

'Department of Cardiology, Guangzhou First People's Hospital, School of Medicine, South China University of Technology, 1 Panfu road, Guangzhou 510180, China. ²Department of Cardiology, Guangzhou First People's Hospital, Guangzhou Medical University, Guangzhou 510180, China. ${ }^{3}$ Department of Cardiology, the Third Affiliated Hospital, Sun Yat-sen University, Guangzhou 510630, China. ${ }^{4}$ Department of Cardiology, the First Affiliated Hospital, Sun Yat-sen University, Guangzhou 510080, China.

Received: 1 March 2020 Accepted: 4 June 2020

Published online: 23 June 2020

\section{References}

1. Gidding SS, Allen NB. Cholesterol and atherosclerotic cardiovascular disease: a lifelong problem. J Am Heart Assoc. 2019;8:e012924.

2. Mach F, Baigent C, Catapano AL, Koskinas KC, Casula M, Badimon L Chapman MJ, De Backer GG, Delgado V, Ference BA, et al. 2019 ESC/EAS guidelines for the management of dyslipidaemias: lipid modification to reduce cardiovascular risk. Eur Heart J. 2020:41:111-88.

3. Wong ND, Zhao Y, Quek RGW, Blumenthal RS, Budoff MJ, Cushman M, Garg P, Sandfort V, Tsai M, Lopez JAG. Residual atherosclerotic cardiovascular disease risk in statin-treated adults: the multi-ethnic study of atherosclerosis. J Clin Lipidol. 2017;11:1223-33.

4. Soran $H$, Dent $R$, Durrington P. Evidence-based goals in LDL-C reduction. Clin Res Cardiol. 2017;106:237-48.

5. Liu C, Li Y, Guan T, Lai Y, Shen Y, Zeyaweiding A, Zhao H, Li F, Maimaiti T. ACE2 polymorphisms associated with cardiovascular risk in Uygurs with type 2 diabetes mellitus. Cardiovasc Diabetol. 2018;17:127.

6. Szeto $\mathrm{V}$, Chen NH, Sun HS, Feng ZP. The role of KATP channels in cerebral ischemic stroke and diabetes. Acta Pharmacol Sin. 2018;39:683-94.

7. Foster MN, Coetzee WA. KATP channels in the cardiovascular system. Physiol Rev. 2016;96:177-252.

8. Yokoyama T, Izumi H, Endoh M, Izawa T, Ogawa N, Okada Y. Effects of KRN4884, a novel pyridinecarboxamidine type KATP channel opener, on serum triglyceride levels in rats. Br J Pharmacol. 1997;120:1471-6.

9. Yue JT, Abraham MA, LaPierre MP, Mighiu PI, Light PE, Filippi BM, Lam TK. A fatty acid-dependent hypothalamic-DVC neurocircuitry that regulates hepatic secretion of triglyceride-rich lipoproteins. Nat Commun. 2015;6:5970

10. Schmitz G, Buechler C. ABCA1: regulation, trafficking and association with heteromeric proteins. Ann Med. 2002;34:334-47.

11. Fryirs MA, Barter PJ, Appavoo M, Tuch BE, Tabet F, Heather AK, Rye KA. Effects of high-density lipoproteins on pancreatic beta-cell insulin secretion. Arterioscler Thromb Vasc Biol. 2010;30:1642-8.

12. Ling MY, Ma ZY, Wang YY, Qi J, Liu L, Li L, Zhang Y. Up-regulated ATPsensitive potassium channels play a role in increased inflammation and plaque vulnerability in macrophages. Atherosclerosis. 2013;226:348-55.

13. Fan LH, He Y, Xu W, Tian HY, Zhou Y, Liang Q, Huang X, Huo JH, Li HB, Bai $L, M a A Q$. Adiponectin may be a biomarker of early atherosclerosis of smokers and decreased by nicotine through KATP channel in adipocytes. Nutrition. 2015;31:955-8.

14. Strom J, Swyers T, Wilson D, Unger E, Chen QM, Larson DF. Dodecafluoropentane emulsion elicits cardiac protection against myocardial infarction through an ATP-sensitive K+ channel dependent mechanism. Cardiovasc Drugs Ther. 2014;28:541-7. 
15. Group IS. Effect of nicorandil on coronary events in patients with stable angina: the impact of Nicorandil in angina (IONA) randomised trial. Lancet 2002;359:1269-75

16. Zhong CJ, Chen MM, Lu M, Ding JH, Du RH, Hu G. Astrocyte-specific deletion of Kir6.1/K-ATP channel aggravates cerebral ischemia/reperfusion injury through endoplasmic reticulum stress in mice. Exp Neurol. 2019;311:225-33.

17. Engwa GA, Nwalo FN, Chikezie CC, Onyia CO, Ojo OO, Mbacham WF, Ubi BE. Possible association between ABCC8 C49620T polymorphism and type 2 diabetes in a Nigerian population. BMC Med Genet. 2018;19:78.

18. Nikolac N, Simundic AM, Saracevic A, Katalinic D. ABCC8 polymorphisms are associated with triglyceride concentration in type 2 diabetics on sulfonylurea therapy. Genet Test Mol Biomarkers. 2012;16:924-30.

19. Xu M, Hu H, Deng D, Chen M, Xu Z, Wang Y. Prediabetes is associated with genetic variations in the gene encoding the Kir6.2 subunit of the pancreatic ATP-sensitive potassium channel (KCNJ11): a case-control study in a Han Chinese youth population. J Diabetes. 2018;10:121-9.

20. Sakamoto $Y$, Inoue $H$, Keshavarz P, Miyawaki K, Yamaguchi $Y$, Moritani M, Kunika K, Nakamura N, Yoshikawa T, Yasui N, et al. SNPs in the KCNJ11ABCC8 gene locus are associated with type 2 diabetes and blood pressure levels in the Japanese population. J Hum Genet. 2007:52:781-93.

21. Smith KJ, Chadburn AJ, Adomaviciene A, Minoretti P, Vignali L, Emanuele E, Tammaro P. Coronary spasm and acute myocardial infarction due to a mutation (V734I) in the nucleotide binding domain 1 of ABCC9. Int J Cardiol. 2013;168:3506-13.

22. Stefanski A, Majkowska L, Ciechanowicz A, Frankow M, Safranow K, Parczewski M, Pilarska K. The common C49620T polymorphism in the sulfonylurea receptor gene (ABCC8), pancreatic beta cell function and longterm diabetic complications in obese patients with long-lasting type 2 diabetes mellitus. Exp Clin Endocrinol Diabetes. 2007;115:317-21.

23. Kullo IJ, de Andrade M, Boerwinkle E, McConnell JP, Kardia SL, Turner ST. Pleiotropic genetic effects contribute to the correlation between HDL cholesterol, triglycerides, and LDL particle size in hypertensive sibships. Am J Hypertens. 2005;18:99-103.

24. Williams RR, Hunt SC, Hopkins PN, Wu LL, Hasstedt SJ, Berry TD, Barlow GK, Stults BM, Schumacher MC, Ludwig EH, et al. Genetic basis of familial dyslipidemia and hypertension: 15-year results from Utah. Am J Hypertens. 1993;6:319S-27S

25. Lang RM, Badano LP, Mor-Avi V, Afilalo J, Armstrong A, Ernande L, Flachskampf FA, Foster E, Goldstein SA, Kuznetsova T, et al. Recommendations for cardiac chamber quantification by echocardiography in adults: an update from the American Society of Echocardiography and the European Association of Cardiovascular Imaging. Eur Heart J Cardiovasc Imaging. 2015;16:233-70

26. Meschia JF, Klaas JP, Brown RD Jr, Brott TG. Evaluation and Management of Atherosclerotic Carotid Stenosis. Mayo Clin Proc. 2017;92:1144-57.

27. Pan Y, Wang T, Li Y, Guan T, Lai Y, Shen Y, Zeyaweiding A, Maimaiti T, Li F, Zhao H, Liu C. Association of ACE2 polymorphisms with susceptibility to essential hypertension and dyslipidemia in Xinjiang, China. Lipids Health Dis. 2018;17:241

28. Ibanez B, James S, Agewall S, Antunes MJ, Bucciarelli-Ducci C, Bueno H, Caforio ALP, Crea F, Goudevenos JA, Halvorsen S, et al. ESC guidelines for the management of acute myocardial infarction in patients presenting with ST-segment elevation: the task force for the management of acute myocardial infarction in patients presenting with ST-segment elevation of the European Society of Cardiology (ESC). Eur Heart J. 2017;2018(39):119-77.

29. Jacobson TA, Ito MK, Maki KC, Orringer CE, Bays HE, Jones PH, McKenney JM, Grundy SM, Gill EA, Wild RA, et al. National Lipid Association recommendations for patient-centered management of dyslipidemia: part 1 - executive summary. J Clin Lipidol. 2014:8:473-88.

30. Reindl M, Reinstadler SJ, Feistritzer HJ, Theurl M, Basic D, Eigler C, Holzknecht M, Mair J, Mayr A, Klug G, Metzler B. Relation of low-density lipoprotein cholesterol with microvascular injury and clinical outcome in Revascularized ST-elevation myocardial infarction. J Am Heart Assoc. 2017;6.

31. Emanuelsson F, Nordestgaard BG, Tybjaerg-Hansen A, Benn M. Impact of LDL cholesterol on microvascular versus macrovascular disease: a Mendelian randomization study. J Am Coll Cardiol. 2019:74:1465-76.

32. Kumar Jha P, Ete T, Malviya A, Kumar Das C, Saha SK, Nath D, Kapoor M, Mishra A. Microalbuminuria: correlation with prevalence and severity of coronary artery disease in non-diabetics. J Clin Med Res. 2017;9:838-43.

33. Ridker PM, Everett BM, Thuren T, MacFadyen JG, Chang WH, Ballantyne C, Fonseca F, Nicolau J, Koenig W, Anker SD, et al. Antiinflammatory therapy with Canakinumab for atherosclerotic disease. N Engl J Med. 2017:377:1119-31.

34. Aday AW, Ridker PM. Antiinflammatory therapy in clinical care: the CANTOS trial and beyond. Front Cardiovasc Med. 2018;5:62

35. Ridker PM, Everett BM, Pradhan A, MacFadyen JG, Solomon DH, Zaharris E, Mam V, Hasan A, Rosenberg Y, Iturriaga E, et al. Low-dose methotrexate for the prevention of atherosclerotic events. N Engl J Med. 2019;380:752-62.

36. Tardif JC, Kouz S, Waters DD, Bertrand OF, Diaz R, Maggioni AP, Pinto FJ, Ibrahim R, Gamra H, Kiwan GS, et al. Efficacy and safety of low-dose colchicine after myocardial infarction. N Engl J Med. 2019;381:2497-505.

37. Wang W, Ren D, Wang CS, Li T, Yao HC. High sensitivity C-reactive protein to prealbumin ratio measurement as a marker of the prognosis in acute coronary syndrome. Sci Rep. 2019;9:11583.

38. Ribeiro DR, Ramos AM, Vieira PL, Menti E, Bordin OL Jr, Souza PA, Quadros AS, Portal VL. High-sensitivity C-reactive protein as a predictor of cardiovascular events after ST-elevation myocardial infarction. Arq Bras Cardiol. 2014;103:69-75.

39. Ormazabal V, Nair S, Elfeky O, Aguayo C, Salomon C, Zuniga FA. Association between insulin resistance and the development of cardiovascular disease. Cardiovasc Diabetol. 2018;17:122.

40. Wan J, Jiang X, Bai J, Shen D, Wang T. The effects of E23K polymorphism in Kir6.2 subunit on insulin sensitivity in skeletal muscle cells by long-chain fatty acyl CoA. Biochem Biophys Res Commun. 2009;381:496-501.

41. Gonen MS, Arikoglu H, Erkoc Kaya D, Ozdemir H, Ipekci SH, Arslan A, Kayis SA, Gogebakan B. Effects of single nucleotide polymorphisms in K (ATP) channel genes on type 2 diabetes in a Turkish population. Arch Med Res. 2012:43:317-23.

42. Ezenwaka C, Kalloo R, Uhlig M, Schwenk R, Eckel J. The E23K variant in the Kir6.2 subunit of the ATP-sensitive K+ channel does not augment impaired glucose tolerance in Caribbean subjects with a family history of type 2 diabetes. J Endocrinol. 2005;185:439-44.

43. Kaufmann PA, Gnecchi-Ruscone T, Schafers KP, Luscher TF, Camici PG. Low density lipoprotein cholesterol and coronary microvascular dysfunction in hypercholesterolemia. J Am Coll Cardiol. 2000;36:103-9.

44. Toth PP, Simko RJ, Palli SR, Koselleck D, Quimbo RA, Cziraky MJ. The impact of serum lipids on risk for microangiopathy in patients with type 2 diabetes mellitus. Cardiovasc Diabetol. 2012;11:109.

45. Severino P, D'Amato A, Netti L, Pucci M, Infusino F, Maestrini V, Mancone M, Fedele F. Myocardial ischemia and diabetes mellitus: role of oxidative stress in the connection between cardiac metabolism and coronary blood flow. J Diabetes Res. 2019;2019:9489826.

46. Rodriguez-Pallares J, Parga JA, Joglar B, Guerra MJ, Labandeira-Garcia JL. Mitochondrial ATP-sensitive potassium channels enhance angiotensininduced oxidative damage and dopaminergic neuron degeneration. Relevance for aging-associated susceptibility to Parkinson's disease. Age (Dordr). 2012:34:863-80.

47. Trinder M, Francis GA, Brunham LR. Association of monogenic vs polygenic hypercholesterolemia with risk of atherosclerotic cardiovascular disease. JAMA Cardiol. 2020;5(4):390-9.

48. Rader DJ, Pure E. Genetic susceptibility to atherosclerosis: insights from mice. Circ Res. 2000;86:1013-5.

49. Albert PR, Le Francois B, Vahid-Ansari F. Genetic, epigenetic and posttranscriptional mechanisms for treatment of major depression: the 5HT1A receptor gene as a paradigm. J Psychiatry Neurosci. 2019;44:164-76.

50. Seki T, Goto K, Kansui Y, Ohtsubo T, Matsumura K, Kitazono T. Angiotensin II receptor-neprilysin inhibitor sacubitril/Nalsartan improves endothelial dysfunction in spontaneously hypertensive rats. J Am Heart Assoc. 2017; 6(10):e006617

\section{Publisher's Note}

Springer Nature remains neutral with regard to jurisdictional claims in published maps and institutional affiliations. 